\title{
Applied Value of Mathematical Modeling Thought in Advanced Mathematics Teaching
}

\author{
Rong Miao
}

Weinan Normal University, Weinan, 714000, China

\author{
Keywords: Advanced Mathematics; Mathematical Modeling; Classroom Teaching
}

\begin{abstract}
Higher mathematics is a basic course for science and engineering undergraduates and agricultural college students. It can be said that the learning effects of advanced mathematics will have a direct impact on the learning of other specialized courses. Therefore, both teachers and students attach great importance to this basic course. However, the characteristics of higher mathematics which are abstract and logical are not only difficult to learn, but also make the students lose their interest in learning. Therefore, teachers should consciously emphasize their applicability in the process of advanced mathematics teaching so as to stimulate students' Learning interest. Mathematical modeling is to apply the mathematical method for a certain area or a practical problem necessary simplifications and assumptions, clear variables and parameters based on an inherent law, the use of appropriate mathematical theory to establish a clear The mathematical relationship between the mathematical model to establish the relationship between the model is modeling. The integration of mathematical modeling ideas and methods in higher mathematics teaching can lead students to combine higher mathematics content with mathematical modeling to improve students 'abilities to find, analyze and solve problems, and enhance students' ability to apply and practice. The article mainly discusses the application of mathematical modeling in higher mathematics teaching.
\end{abstract}

\section{The Problems of Higher Mathematics Teaching}

Influenced by the traditional teaching system, there are still some problems in advanced mathematics teaching in our country at present:

First of all, the teaching content lacks practicability and pertinence. All along, the teaching of higher mathematics in our country mainly focuses on theoretical analysis and problem-solving skills training, ignoring the connection between mathematics and other disciplines and students' daily life, not to mention the cultivation of student's application consciousness and innovation ability. Second, the teaching method is too simple. The traditional higher mathematics teaching class teacher to explain the students accepted, of course, in the imparting of system knowledge, this method is better, but neglected the dominant position of students, students are not motivated to learn, and the ability to solve practical problems can not be forged Practicing, contrary to the concept of emphasizing the role of students in the new curriculum reform. Finally, higher mathematics teaching and student major are out of touch with each other. Because advanced mathematics is a basic course, many schools use the same standard of teaching evaluation, uniform proposition, uniform examination and uniform grading even though their major is different. Teachers use the same teaching methods and learn the same teaching content for all majors, the same teaching progress, the direct result of this approach is to lead to a serious disconnect between higher mathematics and student professional. In fact, students of different majors have different math and majors have different requirements on mathematics. To use the same teaching mode will directly affect the teaching results of advanced math.

\section{The Application Value of Mathematical Modeling in Higher Mathematics Teaching}

The value of applying mathematical modeling in higher mathematics teaching is mainly reflected in the following aspects: 
Higher mathematics as a basic course of its many contents, however, arranged in other closely under the premise of higher mathematics class time is relatively small, and advanced mathematics has theoretical, abstract characteristics of the course, so many students are not interested in learning. Applying mathematics model in advanced mathematics teaching can make students feel the practicability of higher mathematics effectively. For example, the application of golden point theory can guide girls to choose the right high-heeled shoes, or whether the walking speed is faster and the rain is less. This interesting topic is close to the life of students, which can greatly enhance students' interest in learning. To a certain extent, the idea of mathematical modeling is the integration of the application of knowledge in many disciplines. Applying mathematical modeling in advanced mathematics teaching can enrich the teaching content and promote the sublimation of knowledge theory so as to cultivate students' innovative ability and develop their divergence thinking and so on. And the infiltration of modeling thought is mostly based on solving practical problems. Students must collect relevant data through practice in the process of learning, and analyze the problems from the practical point of view, establish the solution model and finally finish the research report. The whole process gives students more practical space, to create more opportunities for cultivating their innovative awareness, greatly improving the efficiency of higher mathematics teaching practice. Finally, improve the overall quality of students. With the development of social civilization to the era of knowledge-based economy, all walks of life in society have higher and higher requirements on the overall quality of talented people. Excellent talented people not only need to master basic professional knowledge and skills, but also have problems of solving problems, practical operation and organization and management ability. It can be said that in the process of using mathematical modeling ideas, students need to perform dynamic brain analysis, hands-on operations and cooperate with others repeatedly, each of which is the process of knowledge application and knowledge updating. Therefore, the application of modeling ideas in advanced mathematics can guide students to apply theoretical knowledge in practice and realize the all-round development of abstract thinking, critical thinking and logical thinking.

\section{The Application of Mathematical Modeling in Higher Mathematics Teaching}

First, the model should be designed to fit the student's everyday life. Mathematical models are closely related to students' actual life, which can greatly enhance the interest of learning mathematics and make students recognize the practicability of mathematics. Mathematical model need not be too much emphasis on professional knowledge, so that students can learn the background of professional knowledge is appropriate, but can achieve better learning results. For example, students majoring in physics can choose models related to physical engineering, while students majoring in economics choose models related to socio-economic phenomena. Second, the introduction of mathematical models follows a straightforward principle. The main role of the model is to start a discussion on the mathematical theory of advanced mathematics, so the introduction of mathematical models should be easy to understand, will not occupy the classroom too much time, so as not to overwhelm. Finally, mathematical modeling should be integrated with the existing teaching content. When designing mathematical models, teachers should base themselves on teaching materials, base their efforts on teaching practice, combine them with the existing mathematics content in a step-by-step approach so as to promote the application of mathematical knowledge.

Higher mathematics contains a large number of mathematical concepts, and most of the concepts are abstract from the practical application, has a rich practical background. In the process of advanced mathematics learning, students' understanding of the concept of mathematics will have a decisive effect on the learning effect. Therefore, the teaching of advanced mathematics concepts is of crucial importance. Usually higher mathematics concepts teaching do not give the concept directly, but the refining process of the concept presented, making the concept of a logical, weakened the concept of abstract features, making it easier for students to understand. For example, the concept of definite integral is abstracted from a lot of practical problems. In explaining the concept of integral not only to introduce some of the teaching materials in the trapezoidal area, such 
as variable speed linear motion cases, but also require students to collect and seek trapezoidal trapezoid Similar examples of area, students through the collection of volume, quality and other related examples, you can consolidate its "partition - approximate sum - the limit of" mathematical thinking.

Teachers will be mathematical modeling well into the process of teaching, the boring mathematical concepts, theorems and nature and the colorful reality of the world, will receive a multiplier effect. Teachers reform the existing teaching methods to fully mobilize the enthusiasm of students. The actual teaching process, on the one hand to play a leading role of teachers, on the other hand to give full play to the main role of students, supplemented by student-based teachers, to encourage students to think actively, boldly put forward questions, strive to solve the problem, change the teacher Students listen to the teaching model to achieve the teacher and student status conversion. Using questions as a starting point for teaching, we propose some forward-looking, enlightening and challenging questions by creating contexts so that students can ask questions in a collaborative manner through exploratory processes of observation, synthesis, analysis, conjecture, analogy, experimentation and discovery analyze the problem and solve the problem, and finally realize the purpose of teaching students to apply what they have learned. Change the traditional blackboard plus chalk plus lesson plans teaching mode, combined with multimedia teaching advanced mathematics classroom teaching vivid and interesting.

When a new product is available, the merchant will adopt various promotional measures to promote the new product at an increased speed. After sufficient product feedback is obtained, the merchant may organize the production or arrange the purchase according to the feedback result to improve the product marketing effect. For example, when a certain brand of air conditioner is on the market, many consumers have no understanding of its performance and quality. As manufacturers continue to increase their marketing efforts, some consumers initially recognize the performance of the product and advertise and attract the people around them How do other unpurchased consumers accurately predict the sales of this new air conditioner? When the teacher throws questions to the students, the students think the following questions: First, which factors will affect the sales volume of the products; Second, based on their own life experience, how these factors affect the sales volume; Lastly, after a period of sales, sales will happen what kind of change. The students make reasonable assumptions and analyzes after discussing each other. Based on the analysis of the merchants, a certain amount of air conditioners are put into use and set as $\mathrm{x} 0$, and the quantities sold over time are respectively set as $t, x(t)$; the market The number of consumers is limited, so the maximum demand $\mathrm{L}$, the number of unused consumers is about $\mathrm{Lx}(\mathrm{t})$; sales rate $\mathrm{dx} / \mathrm{dt}$, sales $\mathrm{x}(\mathrm{t})$, the number of unused Lx (t), the sales rate and the sales volume and the number of unused people is proportional to the product, set the scale factor $\mathrm{k}$, you can get the following formula:

$$
\frac{d x}{d t}=\mathrm{kx}(\mathrm{L}-\mathrm{X})
$$

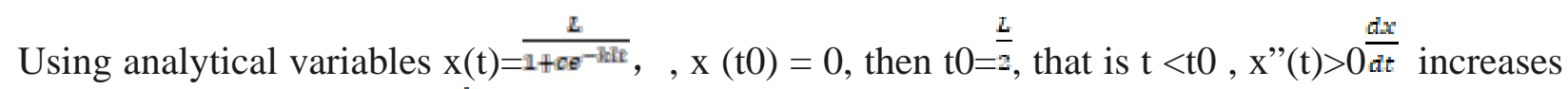
monotonically, ie $x^{\prime \prime}(t)<0$, $\frac{d x}{d t}$ decreases monotonically at $t>t 0$, indicating that when the sales volume is less than half of the maximum demand The speed will continue to rise until the sales volume reaches an increase of the maximum demand, the product is in the best-selling state; after that, the sales speed will slowly decline until it is saturated.

\section{Conclusion}

In short, the application of mathematical modeling in advanced mathematics teaching can stimulate students' interest in learning, cultivate their innovative awareness, improve the fun and practicality of advanced mathematics and mathematics, and enhance their ability to think while developing their thinking abilities. Teachers in the teaching process should be consciously integrated into the modeling thinking, and constantly improve the teaching system of higher mathematics, the courage to try, dare to reform. Of course, follow-up teaching process, the vast 
number of educators still needs to continue to explore and study in order to better play the role and value of mathematical modeling ideas, so as to foster students' innovative thinking and develop their innovative potential.

\section{References}

[1] Li Dasheng, Integrating Mathematical Modeling Thought into Mathematics Main Course [J]. Journal of Mathematical Engineering, 2015, (8).

[2] Cheng Xiaohong. Timeliness of Permeating Mathematical Modeling in Advanced Mathematics Teaching [J]. Microelectronics Science and Management, 2016, (10).

[3] Han Minglian. Mathematical Modeling in Advanced Mathematics Teaching [J]. Journal of Mathematical Medicine, 2016, (10).

[4] Yao Xinqin. Mathematical modeling thought in higher mathematics teaching [J]. Journal of Guangdong Polytechnic Career and Vocational College, 2017, (4).

[5] Cai Wenrong. Mathematical Modeling and Applied Talent Training [J]. Journal of Minjiang University (Natural Science Edition), 2016,27 (2).

[6] Li Da-Qian. Integrating Mathematical Modeling Thought into Mathematics Main Courses [J]. Journal of Engineering Mathematics, 2015,12

[7] Cao Dianli. Understanding and Practice of Integrating Mathematical Modeling Thought into University Mathematics Teaching Content [J]. Journal of Zhoukou Normal University, 2017,24 (5) 